\title{
How Participatory Practice can Help to Strengthen the Role of Volunteering in Sustainable Development: An Organisational Perspective
}

\author{
Katie Turner
}

\begin{abstract}
The post-2015 development debates highlight that the experience of the poorest and most marginalised is one of exclusion due to power inequalities and discrimination. The Valuing Volunteering study demonstrated that volunteering has the potential to challenge power imbalances and strengthen ownership over change for individuals who are traditionally excluded from decision-making processes. However, this article also explores some of the barriers to this approach, such as paternalistic models of volunteering that seek to present the volunteer as the 'silver bullet'; or the pressure to respond to the top-down agendas of governments and donors that are not aligned with the needs on the ground. The article will look at how participatory practice - reviewing existing mechanisms within VSO programmes as well as some new approaches trialled through the Valuing Volunteering research - can help to overcome some of these barriers and the opportunities and challenges of embedding participatory approaches within an international organisation.
\end{abstract}

\section{Introduction}

Valuing Volunteering was designed with two principal aims in mind: to contribute to learning for Voluntary Service Overseas (VSO) and organisations working with volunteers on the role of volunteering in the current development context, and to test new and review existing ways of embedding learning, action and reflection into how we design, implement and review development programmes. Engaging with over 3,700 participants over the two years, the research worked with volunteers and VSO's primary stakeholders - local non-governmental organisation (NGO) and civil society organisation (CSO) partners, teachers, health workers, children, parents, youth - to create spaces for reflection and action at a local level. While many of the lessons learnt from the process of conducting the research are likely to be applicable to the wider development sector and organisations working with volunteers, this article will primarily focus on VSO's organisational response to some of the implications it raised and build on our existing analysis of these issues.

The article will look at some of the factors that are encouraging a move away from participatory practice such as a growing pressure on international non-governmental organisations (INGOs) and their partners on the ground to be more upwardly accountable to donors and governments (Anderson, Brown and Jean 2012). It will consider the extent to which this has encouraged a more paternalistic, instructional model of volunteering (Devereux 2008: 358) with the expectation being set from the top down that the volunteer is coming in to provide solutions, discouraging those working with the volunteer from putting forward their own ideas and solutions. The drive to respond to top-down pressures was also seen to affect the types of local partnerships that were formed, with a preference often displayed towards partners that had the right infrastructures in place but who, in practice, were not necessarily representative of the needs of the most marginalised. This article looks at whether opening up spaces for dialogue and reflection within communities can help to identify and address local power dynamics within the parameters of a particular intervention.

In addition to developing and testing new participatory approaches, Valuing Volunteering provided the opportunity to test existing academic 
and practitioner theories (Devereux 2008: 359-60; Lough and Matthew 2013: 16) about what makes volunteering well placed to facilitate a participatory approach. These theories, also reflected in VSO's theory of change (VSO 2014), suggest that through their immersion and embeddedness within communities - volunteers can act as a powerful mechanism for building and strengthening the ownership, participation, empowerment and inclusion, which are necessary for systemic and sustainable change to happen (Howard, Lewis and Burns 2015). The article also looks at the ways in which the research approaches - participatory systemic inquiry (PSI) and systemic action research (SAR) - were used to develop volunteers' skills as participatory practitioners. For example, training them in how to conduct community inquiries and use systems thinking to look at the factors contributing to or hindering the impact of a particular volunteer intervention.

Valuing Volunteering offered a unique opportunity - with four researchers working in the field, full-time over a two-year period - to look at how processes of reflection, action and learning could be embedded within volunteer interventions. However, when we consider how we might embed participation within VSO programmes in the long term outside the parameters of Valuing Volunteering, the way in which programmes are currently constructed within VSO present some challenges that will need to be overcome in order to do this effectively. For example, an increasing pressure on organisations to set out the intended outcomes and model for delivery before a project is under way, and sometimes even demonstrate results before funding is provided, can limit the opportunity to be flexible and responsive to emerging need. Another factor is the growing diversity of the volunteering for development sector. While this provides a real opportunity for the formation of multidisciplinary teams of volunteers, Valuing Volunteering demonstrated that the different volunteer interventions frequently remain unconnected. This lack of joined-up thinking between interventions was seen to act as a barrier to participation, diverting community resources to supporting or responding to a series of different interventions rather than encouraging collaborative efforts. This article will attempt to offer some realistic solutions to these challenges, looking at how participation can be embedded within programmes within the context of competing tensions between a top-down versus bottom-up approach to development.

\section{Competing priorities; barriers to participatory approaches}

In recent years, the pressure on the development sector to professionalise has steadily increased in order to support standards of consistency, predictability and professionalism across programmes and contexts (Anderson et al. 2012). While professionalisation may have led to NGOs and INGOs streamlining and simplifying processes and functioning more efficiently, there is a risk of losing sight of the values that these systems were set up to support (ibid.) as an emphasis on efficiency shifts focus away from the realities on the ground, and reduces the ability of NGOs and INGOs to be flexible and responsive to the need of aid recipients.

\subsection{Top-down vs community-led approaches}

Lewis's research exploring community-based volunteering in Korogocho found that development organisations coming into Korogocho rarely actively engaged or consulted with local volunteers and local people:

What engagement does occur is generally seen by the community as tokenistic with the result being failed projects, wasted resources and the creation of a competition culture between volunteers that discourages any expression of views that may vary from the prescribed approach. 'They come and they think they know what we know, they know our priorities... they even give some small funding even though it will be phased out after year one... they give no thought to sustainability' (Member of local self-help group) (Lewis 2015: 64).

The research found that where organisations had claimed to engage primary actors in defining topdown objectives, this was frequently done through consultation rather than participation. In many cases, when external organisations entered a community to set up a new project or to review the progress of an existing project, we found that the poorest and most marginalised in the community were only superficially consulted, and that the project objectives had already been predefined. At other times poor and marginalised people were entirely excluded from decision-making processes, with only those in positions of power in the community being engaged by organisations. Lewis suggests that underlying this lack of engagement is a perception that external organisations know what is best:

As one respondent commented, 'the vision of any NGO when they come to the slum is to transform it and improve the standards.' The most high 
profile example of this in recent times has been the Korogocho Slum Upgrading Programme (KSUP). Although the programme has led to visible changes in Korogocho such as new roads, a footbridge and more recently a health centre... many residents feared the construction of more permanent dwellings because of the likelihood of increased rental charges and the requirement to pay utility bills (Lewis 2015: 64).

Lewis's example demonstrates that often an organisation's understanding of development is not the same as ideas held by the community, some of whom, as Lewis notes, would prefer to live in an informal settlement as they can access low rents and cheaper utilities. The Korogocho example also highlights how, even when there was some form of engagement, it often only involved those in positions of power: "Many NGOs identify a place like Koch but they don't engage with people on the ground. They only engage opinion leaders... often the opinion leaders don't know the feeling on the ground" Community Health Worker' (Lewis 2015: 65).

Organisations and donors' response as to why they frequently make do with these more tokenistic consultation processes is often that they are bound by time or resource pressures, needing to respond to short project proposal time frames with much of their own time consumed by writing proposals or reports (Anderson et al. 2012: 126). The fact is, investing in genuine community engagement does require time and resources, yet often external organisations and donors focus on the end outcomes and not the process. The Valuing Volunteering research suggests that while time and resource challenges are very real, prioritising and nurturing the right skills within existing volunteer resources in order to embed participation is necessary. In reflecting on how they worked with their Nepali colleagues, international volunteers said that it was sometimes difficult to not adopt a more instructional approach when the volunteers were 'put on a pedestal' and seen as the people with the solutions (Hacker 2014: 28). One VSO volunteer acknowledged the importance of reflection in this context:

My [volunteer] placement is creating this attitude and language of superiority... You have to take such a self-reflective look at yourself as a volunteer and an individual... but we are not provided with enough training where we know to constantly reflect.

Hacker notes that while pre-placement training, joint planning requirements and orientations certainly emphasise relationship building, organisational systems tend to focus on outputs, and are not balanced by process monitoring that looks carefully at the approach. There is therefore little incentive or support for volunteers once on placement to reflect on how they are working. Knowing how to take a participatory approach is a very specific skill set and not all volunteers, even after having received some initial training, will immediately know how to translate this into practice. 'Listening is challenging. It takes time and energy, it demands attention and receptiveness, and it requires choices... a discipline that involves setting aside expectations of what someone will say' (Anderson et al. 2012: 7). As a result, volunteers' approaches are often highly individualised:

There were examples described and observed of volunteers working in highly participatory ways, and also of volunteers working in very resourcebased and directed ways. Volunteers interpret their roles and responsibilities very differently depending on a wide range of factors (their cultural, educational and professional background, personality type, view of development, Nepali proficiency, etc) (Hacker 2014: 47).

Hacker's case study also suggests that existing local perceptions about the superiority of external versus local knowledge can also make co-construction challenging; "The volunteer is an inspiration, we have nothing to teach her... we don't have much knowledge. I would have nothing to teach her because she knows more" Teacher, hill district' (Hacker 2014: 49).

VSO and some of the other organisations engaged in the research were often placing an emphasis on promoting the technical expertise of volunteers over and above the more relational aspects of their role, as their technical skills were seen as the more 'visible' assets and are easier to communicate and promote to donors. This is not to diminish the importance of these technical skills, but there is a risk that if too much emphasis is placed on technical inputs and outcomes when programmes and volunteer recruitment processes are designed, then ways of working become an afterthought and add on at the end. In order for participation to be truly embedded within programmes it has to be integrated into each part of a programme cycle. As the testimonies in the IDS Knowledge from the Margins report demonstrate, ongoing collaboration and co-production comes from a demonstrated commitment to empowerment, not just service delivery, and a willingness to devote 
the time and energy needed to work in collaboration (Shahrokh and Wheeler 2014: 21-2).

\subsection{Reaching the poorest and most marginalised: identifying the right partnerships in development}

The Valuing Volunteering research found that the ability of volunteer interventions to effectively contribute to development outcomes, and to reach the poorest and most marginalised, was often reliant upon the partnerships that were formed within a particular programme, and whether these partners espoused the same values of participation and understanding when considering how to put such principles into practice. The research explored two types of partnership commonly reflected within the volunteering for development sector:

\section{Partnerships between volunteering for} development organisations and local partners or institutions hosting or working alongside the volunteers; and

\section{Partnerships between national volunteering} bodies, both government and academic, and local NGOs or public service bodies.

One of the challenges identified was that the formation of these partnerships was often dependent on whether partners are perceived to have the right infrastructures in place to deliver on the intended outcomes, rather than whether they share the same 'people first' principles about empowering primary actors to have a voice over what, how and when development is delivered (VSO 2010: 6). Picken's case study, which examines a community volunteering project in Mozambique, describes the different brokers and partners that the INGO went through in order to undertake the project within the community:

The association [local NGO] stipulated by the Secretario Do Barrio [local leader] had 15 members and a legalised and recognised statute which means that it was easier for the supporting volunteer development agency to implement the project through them (Picken 2015: 12). ${ }^{1}$

These members of the association were made up of various other local leaders and influential figures within the community. Although some community members (some of whom were later engaged as volunteers) had been involved in conducting the initial problem identification and risk assessment as part of the design of the project, there appears to have been limited or no engagement beyond the point when partnerships and other local stakeholders were being agreed upon. There was general acknowledgement among those community members involved of the need to work through existing local structures in order for the project to be supported and facilitated by the local leadership. However, the fact that the community did not appear to have a genuine voice within the partner identification process meant issues that might have been identified at the time regarding the power relationships between the local partner and wider community did not emerge until later, when the project was well under way. The community members that then became volunteers in the project described how the local partner organisation took control of strategic decisions regarding where the activities would be conducted, and how available resources would be divided. For example, the partner made the decision without consultation to locate the activities at a distance from most volunteers' homes and in a location that was closed off from the community. This was in opposition to a request from the volunteers that the activities be located closer to their homes so that they would not have to spend too much time away from their existing livelihoods and responsibilities at home. The closed off location of the activities also meant that members of the community who intended to access the training and support the project had been set up to provide were either unaware of (the chosen location was behind a highwalled gated compound) or unclear about their right to access the activities.

There were strong intimations from the volunteers involved in the project that a lot of decisions being made by the partner organisation were driven by the partner's interest in using the project to promote their own political agenda. The civil society context in Mozambique is often highly politicised with some political parties making use of CSOs to advance their political interests (Open Society Institute Network 2009: 68). In the case of the community volunteer project it was therefore always likely to be a risk that potential civil society partners may have their own sub-agendas, or have been co-opted in some way by the political interests of others. This does not mean that organisations like VSO should simply choose not to work in these communities. If anything, the case for working within these communities is often stronger, as individuals are suffering greater marginalisation as a result of political divisions; however, local agendas have to be a factor against which potential partnerships are assessed and selected. Genuine engagement with communities that specifically targets those that are the most marginalised (who in this case may well be those who are not affiliated with the dominant local political party), can help to bring 
these issues to light and identify the partnerships that are representative of these groups. The Valuing Volunteering Mozambique researcher facilitated a series of workshops involving volunteers who were engaged in the project. The aim was to unpack some of the systemic issues that had been identified as challenging the effectiveness of the project and to collectively identify ways in which some of these challenges could be overcome. However, because these workshops were conducted at a point when the local association had already been given the mandate to oversee the project, this imposed considerable limitations on the researcher's ability to create open and safe spaces for dialogue:

$[\mathrm{T}]$ he power play that was present in the community made data collection very difficult... access to the project documents, site and stakeholders was highly monitored and controlled by several stakeholders (Picken 2015: 29).

Once the local association realised that the objective of the workshops was about facilitating open and honest dialogue about the factors challenging local ownership over activities and how to overcome these, they tried to usurp this space, ensuring that certain local leaders were present at meetings in order to oversee what discussions took place. While the researcher may have been challenged in creating spaces for engagement and reflection had this process been undertaken before the project was under way, it is still a useful mechanism for identifying the potential power struggles that are at play. In the recommendations made by VSO's People First Programme Architecture (PFPA) project and its Participation and Governance Review (Coysh 2015: 27; Howard et al. 2015: 18) they propose that VSO builds on the Valuing Volunteering methodology and recruits a cohort of volunteers on an ongoing basis who can take on the role of action researchers and facilitators. These volunteers could then undertake a similar role to the Valuing Volunteering researchers, working with partner organisations to develop the understanding and skills required for participatory approaches. Such an approach will help to shift VSO's focus to assessing and building on partners' governance and participation credentials, rather than solely on their capacity to deliver.

\section{Using participatory approaches to strengthen the design and implementation of volunteering for development programmes}

Valuing Volunteering used two research approaches to collect and analyse insights about volunteering:
PSI and SAR (Burns 2007). As well as enabling us to understand how change happens, trialling these approaches provided us with insights into how they could be used to strengthen the implementation of VSO's theory of change (TOG).

\subsection{Taking a systemic perspective and testing theories of change}

One of the challenges identified through the Nepal research was that while there had been recognisable improvements in schools as a result of the work being carried out by the teachers and VSO volunteers, some of the systemic factors that were the cause of other issues, such as low school attendance or children's low levels of concentration, had not been taken into consideration. Hacker describes how the action research process enabled assumptions to be tested and theories of change to be adapted in real time:

In the semi-rural school, at the first meeting one point discussed was that parents who were illiterate seemed less likely to send their children to school. Parents and teachers felt that they could encourage parents to attend literacy classes as a long-term aim to improve the culture around valuing education in the community. At the next meeting... the parents reported that some women's movement was restricted by their husbands and they were not allowed to leave the house to attend the classes. We discussed how our theory of change could be adapted in light of these insights (Hacker 2014: 48).

\section{VSO's current TOG for education recognises} that increased access to, and quality of, education services and resources has to focus on solutions in the classroom - increasing the number of qualified and trained teachers and educators and outside of the classroom - working with poor communities, including parents and youth, to raise awareness about the rights to education and address socioeconomic barriers to enrolment, attendance and retention. However, what it doesn't do, and arguably cannot tell us, is how these issues play out at a micro level, and how in every new context the issues will be slightly different and driven by different systemic factors. What the action research approach used in Nepal allows us to do is test and amend the TOC as a project progresses.

An interesting insight was that the structure of the International Citizenship Service (ICS) programme, which engages young volunteers from the UK and the global South in three-month projects, meant 
that it was well set up to feed into TOC learning. Despite the short-term nature of the projects, cycles of reflection, action and learning have been built into the programme, making it easier to incorporate participatory approaches into these existing processes. Aked reflects on how the training she provided to one group of young people enabled them to take a more critical approach to the work they were undertaking:

They used the data generated from these techniques over the course of a three-month placement to support iterative learning about how to be effective in their work... The opportunity to look at volunteering as part of a wider social system initially prompted reflection on the limitations of volunteers' own role and position. Some volunteers rewrote their placement descriptions. This opened up a whole-group discussion about what was achievable within three months, and what their focus should be given their desire to leave some sort of sustainable impact (Aked 2014: 64).

Examples from both Nepal and the Philippines highlight the importance of being able to test and adapt theories of change once projects are under way. They are theories after all and what may be effective and appropriate in one context or at one point in time may not apply in another. Training volunteers, both international and national volunteers recruited by VSO, but also those community-based volunteers (as demonstrated through the Kenya research), engaged in VSO projects, in how to apply systems thinking and action research, is one way in which this process can be supported as it provides them with the tools to think more critically and adapt their approaches. However, these skills and decisions should not solely reside with the volunteers. As part of its PFPA project, designed to strengthen evidencebased programming across VSO programmes, VSO has developed a new programme cycle which emphasises the need for reflection, research and analysis to be embedded and returned to throughout the programme cycle. VSO aims to ensure this process does not only reside with the volunteer(s) or programme managers, but that partner organisations, together with the communities they serve, as in the Nepal example, are being supported to undertake action research to identify issues, action and resourcing needs, specifically, whether there is there a need for a volunteer(s) to support this work.

\subsection{Building on existing participatory approaches within VSO}

When VSO commissioned the Valuing Volunteering research it was not only looking for 'new' ways of embedding participation within their programmes, but to also test some of their existing approaches and hypotheses about the factors that contribute to change that is locally owned and sustained. Perhaps one of the most recognisable aspects of the VSO volunteering model, and a characteristic that is reflected in many other volunteering for development organisations' approaches, is the idea that when volunteers are embedded within the communities and organisations in which they are living and working, this creates certain conditions for change which are potentially well placed to facilitate participatory, bottom-up approaches to development (Devereux 2008: 359-60; Lough and Matthew 2013: 16). This approach is closely tied to community development theory, which believes that a participatory approach begins at the level of the community and is based on values such as dignity, respect, trust and reciprocity (Ledwith and Springett 2012: 14). Evidence from Valuing Volunteering strongly supported this theory and provided new insights into the types of outcomes that contributed to these conditions. Hacker highlights in her Nepal education case study how the personal relationships formed between a volunteer and her colleagues helped to create a more balanced relationship:

The power relation is very different between a volunteer eating in the home of the teacher they work with, in the informal sphere, for example, and in the classroom, where the volunteer is often seen as the 'expert.' One volunteer explains how personal relationships could change the nature of the relationship with teachers: 'They wanted to share their family life with you... getting to know their family made it easier to be like guiding and supporting a friend. It made it a lot easier for me.' - VSO volunteer (Hacker 2014: 23).

Examples from other case studies of how these relationships between volunteers and those they were working alongside were cultivated include: volunteer groups in Korogocho conducting outreach work to strengthen the community's understanding of the work they are doing; and a national volunteer in Nepal who spent her weekends at local festivals and gatherings in order to get to know and be known by the communities. Such instances demonstrate that volunteers' embeddedness can impact on their ability to work in a relational way, and is something that applies to all types of volunteers and across all 
contexts. This does not mean, of course, that an individual automatically becomes a participatory practitioner by default of being placed within a community. As demonstrated by the Nepal examples earlier on, this also requires a self-awareness and ability to reflect on the individual's role in order for them to understand the context in which they are working, and recognise the potential power imbalances that may prompt others to see the volunteer as the 'expert', or mistrust their motivation for volunteering. However, if we acknowledge that volunteering is a relational rather than purely technical approach to development, largely reliant upon volunteers' embeddedness within communities, then VSO needs to take a closer look at what it is doing to nurture these skills.

\subsection{Strengthening the role of volunteers as participatory practitioners}

One of the core aims of the Valuing Volunteering research process was to use it as an opportunity to build the capacity of local volunteer groups, NGOs and VSO volunteers to conduct research, and apply the PSI and SAR methodologies. The learning from this process was documented throughout with the intention that it would provide some valuable insights into ways in which VSO could strengthen bottom-up programming by building on the role of volunteers as participatory practitioners. In Lewis's Korogocho research he worked with a communitybased organisation to build links with local volunteer networks that had an interest in forming a research group. He provided the members of this research group with training in participatory techniques and encouraged them to be the ones steering the research process. This gave them ownership while the training in systems and critical thinking enabled them to deconstruct and better understand the complex factors that caused poverty in Korogocho, and to identify the most appropriate actions in response (Lewis 2015: 93). Lewis acknowledges that the process was not without its challenges:

Over the course of the research a number of members of the research team changed jobs, completed studies or secured new opportunities... [this] did present a challenge to the research in terms of maintaining the team's dynamics (Lewis 2015: 94).

Lewis also expresses the fact that it took much longer than first anticipated to build an understanding of the complexity of the local context. This is a potential challenge in the current environment of time-bound projects and short project funding cycles where there is a constant focus on 'new' projects rather than developing those already in existence over time (Ledwith and Springett 2012: 16). However, there is increasing recognition of the need to do this groundwork before projects can get under way, and the need to focus on longterm partnerships rather than only on short-term interventions. A possible solution to this challenge might be to look at how funding that is not tied to a specific project could be ring-fenced specifically for this purpose.

In addition to strengthening our understanding of the conditions and skill sets required that would support volunteers to be participatory practitioners, the research also suggested that there are certain characteristics that make volunteers already well placed to take on this role. Reflecting on an earlier finding in this article - that the ability to apply participatory approaches is often highly individualised and requires specific skill sets - Aked's research with youth volunteers in the Philippines showed that the characteristics of young people potentially make them well placed to apply certain participatory approaches:

Young people are very good at systemic thinking. The ICS volunteers were able to map out issues and connections based on their research really rapidly. It is impressive to watch. In Valuing Volunteering Philippines' experience, adults spend a lot of time worrying what to put where... They were effective at explaining activities and comfortable holding the quiet, disconcerting spaces that usually follow while people figure out what we are asking them to do (Aked 2014: 67).

Critical reflection is an essential component of taking a participatory approach and understanding one's own positionality, but it is often an uncomfortable and challenging process and can be consciously and unconsciously resisted (Ledwith and Springett 2012: 155). Aked suggests that this process of 'unlearning' and challenging existing perceptions is something that young people are potentially more comfortable doing (Aked 2014: 61). One of the implications identified through Valuing Volunteering was the need for organisations working with volunteers to recruit volunteers based on their participatory skills and experience and not only based on their technical skills. However, what the research also suggests is that rather than expect each volunteer to come with the same participatory skills and experience, instead we should be identifying and build upon their individual attributes. 


\section{The challenges and opportunities for embedding participatory approaches within VSO programmes}

Over the years VSO's volunteer interventions have diversified in response to global volunteering and global development trends to include South-South, national, youth volunteers and community-based volunteers. At the same time, its transition from a volunteer-sending organisation to a development organisation that works through volunteers means they are now accountable to a whole new set of stakeholders that includes governments, donors, NGO and INGO partners, corporates, etc each of whom have their own set of interests - either in the outcomes for the volunteer or in the outcomes of the particular project they have invested in. This section explores two potential challenges that these shifts in VSO's engagement in the volunteering for development and broader development environment pose for embedding participatory approaches.

\subsection{Volunteer teams rather than individual inputs}

The Valuing Volunteering research highlighted numerous examples demonstrating that volunteering is rarely an individual effort, and is more often than not reliant upon multidisciplinary volunteer teams (Burns et al. 2015: 28). This reflects the idea that participatory approaches are also about collective action that builds alliances across difference (Ledwith and Springett 2012: 17). Alliances included teams of volunteers from both within, and recruited from outside of a community. For example, Aked (2014: 37) observed that within a single project in the Philippines focused on understanding and raising awareness about declining fish stocks, volunteers with the following skills and experience were involved:

volunteers with knowledge of marine sanctuaries;

- people who could carry out ecological checks;

- people with knowledge of livelihood projects;

- experts in community organising;

people with local knowledge; and

- people who knew about volunteer management.

Identifying and working with local volunteer teams that mobilise a wide range of resources both within and outside of a community is a departure from VSO's previous model of identifying specific technical skill gaps within a programme and then searching for volunteers to fill these gaps, and is more in line with models of community organising and mobilisation. This is not to suggest that VSO and organisations working with volunteers should only recruit or deploy volunteers in teams, but rather that volunteers need to be connected to each other in their efforts, and in particular connected to building the capacity of local volunteer networks who are often themselves from the poor and marginalised communities that we are seeking to reach. So when designing a project, VSO should start with an understanding of existing local volunteer resources, explore how these infrastructures can be supported, and then work outwards from this point to understand if resources and volunteers need to be brought in from outside, and if so how they will interconnect with local groups and networks.

The need for considering the interconnectivity of its volunteer interventions is more crucial now than ever as changes in the volunteer landscape have seen the range of volunteer interventions that VSO engages with grow and diversify. This list includes: short-term corporate volunteer placements; International Citizen Service (ICS), the flagship youth volunteering scheme; the Department for International Development (DFID); and government or academic-run national volunteering schemes; as well as an increasingly diverse range of skilled international volunteer placements. Although there is a real opportunity through the process of volunteer recruitment and training to recruit and support volunteers to employ participatory approaches in their work, and to connect with each other, there is a challenge to managing this process consistently when each of these separate interventions have slightly different approaches to programme design, volunteer recruitment, preparation and partnership development that are layered on top of the overarching programme objectives. For example, earlier in this article we discussed the opportunity for volunteers to build strong relationships within communities, and more collaborative working arrangements, through their embeddedness. Yet increasingly, trends for shorter-term volunteering placements, from three months to three weeks, or sometimes as short as one week mean that some volunteers do not have the same opportunities as those on much longerterm placements, or those volunteering within their own communities, to understand the development context and to build these relationships.

The funding preferences of donors, and in some cases of volunteers or their employers, for short project time frames, means it is difficult to challenge 
these time frames. This therefore potentially places an even greater onus on VSO to ensure they carry out the groundwork needed outside of the volunteer placement, such as taking direct responsibility for building relationships with the local partner and communities to strengthen their understanding of the work the volunteers are coming to do, and to ensure that they are appropriately placed. For some of the more specialist volunteer placements, such as VSO's political volunteers (Pol Vols), members of parliament (MPs) and decision-makers recruited to volunteer on a short-term assignment of 5-10 days, a lot of work goes in to preparing logistics, and towards setting clear expectations on both sides, and building relationships in advance. The reality is, also, that some of these interventions, particularly those that are more short term, may be more focused on providing very specific technical inputs. However, they must therefore be connected to those volunteer interventions that are more focused on building relationships and trust and strengthening ownership and agency at a local level.

\subsection{Participation as a principle and not just an afterthought}

While taking a programmatic approach has enabled VSO to strengthen its focus on the specific areas of development where it believes it can have the greatest impact, there is a risk if not managed in the right way that it creates more top-down pressures, and can limit the ability of programmes to be flexible and responsive to needs on the ground. As noted in VSO's Participation and Governance Review, the experiences of people living in poverty cannot be neatly compartmentalised into thematic areas, and projects need to have the flexibility to transition across thematic areas in order to be effective (Howard et al. 2015: 12). An internal review of VSO's programmes (Van Eekelen 2015: 23) also identified the fact that the priorities of the most disadvantaged people and communities are not a consistent focus across all programmes. Aked's case study of VSO's contribution to a natural resource management project in the Philippines observed:

We find a situation in Carood watershed where the process of investing and supporting youth volunteers was, at least initially, disruptive to realising priority objectives in the local strategic framework. ${ }^{2}$ Carood Watershed Model Forest Management Council (the partner) has never really been in a position to negotiate what kind of volunteers come, how many volunteers come, when they come, how long they stay or what strengths they have. These factors are either all fixed at the point of funding (e.g. volunteer numbers) or unknown until the point of volunteer arrival (e.g. volunteer strengths) (Aked 2014: 45).

If local stakeholders are not engaged at the start of a project and programme objectives, outputs and timescales are set centrally and then rolled out (as happened in the case of the Philippines example), it sends a clear message to these local stakeholders that they are not being given the agency to make decisions as the inclusion of local perspectives is limited by existing project parameters. However, the reality is that VSO's survival, as with many other INGOs, is reliant upon its ability to diversify its funding streams. This means having to respond to an increasing trend among private and public sector donors to demonstrate factors such as cost-effectiveness, scale-ability and value-add before a programme is even under way. Taking a programmatic approach is perceived to make it easier to demonstrate these factors as it requires the intended outcomes and impact to be pinpointed at the start of a project and provides a 'model' for achieving these outcomes which can be packaged for donors and scaled up over time. But, as critiques of funding models such as Payment by Results have argued, placing these kinds of rigid demands, and in some cases expecting proof of results before payment is released, presents an increasing risk and administrative burden on organisations and partners whose failure to deliver within the allotted time frames could see them actually facing a loss and ending up worse off than where they had started. It also runs counter to participatory approaches that are about exploring non-linear realities and embracing the unintended outcomes (Chambers 2014). A recent independent internal review of VSO's programmes noted that VSO's increasing reliance on restricted programme funding means that VSO country offices face heavier and more diverse pressures than they have faced in the past as the 'sheer number of voices' (Van Eekelen 2015: 6) within VSO programmes has increased:

There used to be a partner and a head office. Now there are also increasingly vocal host governments, regional offices, and a multitude of donor agencies... as a result partnerships in general and the monitoring of volunteer placements received less attention than they have received in the past (ibid.: 4).

As VSO faces a reality where this number of voices is likely to grow rather than diminish in coming years, there is a need to find a balance between 
acknowledging the need to take a programmatic approach while finding ways to build in more flexibility and space for reflection and participation within these frameworks. This could include freeing up staff time to spend more time in the field, and working with partners and communities to undertake PSI that will strengthen understanding of the local context and ownership over the programme design process. But it is not just about ensuring that a participatory approach is taken at the start of a project; it is also that the approach is being consistently applied and tested throughout a programme cycle. As highlighted by Aked, the volunteer can play a key role in helping to maintain this momentum:

It is easier to show people how the volunteering system works by inviting them to actively participate with volunteers in development efforts. But this approach assumes a willingness on the part of the community to engage in the first place. An iterative approach to community development may have to actively build this interest, which takes time and initiative on the part of volunteers. It can challenge volunteers' own perceptions of what they will be able to achieve during placement (Aked 2014: 56).

When individuals feel informed, they feel respected and able to participate more effectively (Anderson et al. 2012: 121). This has to be a principle that is reflected as a way of working for VSO across everything that the organisation does. Yet, even within the Valuing Volunteering research the participatory principle is something that VSO has at times aspired to, but fallen short of. For example, although when the researchers remained in-country they were extremely committed to feeding back and facilitating collective analysis of the research findings, there was still a sense among some researchers that once they left the country, some of the momentum for continuing this research would be lost. In addition, we made a commitment to publishing each of the individual case studies that were conducted, and to sharing the final outputs with each of the groups involved in conducting this research. However, the time it has taken to publish each case study, and the cost of getting them translated in some cases, has meant considerable delays in feeding back to these groups, and a sense in some cases that the process has been largely extractive. Learning from this, there is a need to set clear expectations and be transparent about the process at all stages. Importantly, we must invest the time and resources at the beginning to look at how stakeholders will be engaged throughout, even after a specific project has come to an end. For example, success stories from Valuing Volunteering include the Korogocho research group, some of whom now act as critical friends to VSO, as well as engaging in sector discussions about how to create an enabling environment for volunteering in Kenya. The Korogocho example provides a potential model for ongoing engagement that could be replicated across other VSO programmes, encouraging us to not only think in terms of project time frames but to consider long-term partnerships with local partners and communities that provide the opportunity for ongoing collaboration and engagement. As the Philippines research highlighted, 'long-term relationships are not always indicators of dependency... and, as a resource for development, volunteering needs to find more consistent and coherent ways of sharing the risks of experimentation' (Aked 2015: 8). By sharing these risks people from the poorest and most marginalised communities are more likely to be willing to engage in these projects and feel as though they have a genuine opportunity to test out new approaches and ideas.

\section{Conclusion}

As the pressure on INGOs to professionalise has increased, a more business-like model of international development has emerged which prioritises the ability to demonstrate maximum return on investment within strict time frames. As we have seen from Valuing Volunteering, while this might yield visible short-term outputs and outcomes, it potentially places some major constraints on the ability of organisations like VSO to embed processes that will enable local ownership and leadership over projects. We found that one way to redress the balance of the top-down vs bottom-up relationship was for VSO to invest more heavily in volunteers' role as participatory practitioners and incentivise volunteers to be more self-reflective about their positionality in relation to others by evaluating how they are working as well as what they are doing. Identifying the right local partnerships - ensuring that they share the same commitment to poverty alleviation and working with the poorest and most marginalised groups and not simply partnering with them because they appear to have the right infrastructures in place to deliver on the intended objectives - was also seen to be an under-acknowledged but vital factor in empowering primary actors to have a voice in what, how and when development interventions are delivered.

The ability to trial action research and systems thinking methodologies in different contexts and with a diverse range of stakeholders provided 
valuable insights into how VSO could use participatory approaches to strengthen the design and implementation of its programmes. By not going into communities with a predefined idea of what the research would focus on at a local level, researchers were able to provide local groups with the tools - training them in how to construct systems maps and conduct community inquiries - to conduct their own analysis of the local issues and come up with suggestions as to how and where volunteer interventions were best placed to contribute to change. It enabled theories of change to be tested in real time, adjusted and adapted accordingly as new issues emerged, or to look for more effective ways to tackle existing issues. Researchers also encouraged volunteers to reflect on how they were working and to reflect on the factors that were contributing to or hindering their ability to take a participatory approach. We found that VSO's longstanding model of supporting volunteers to become embedded within communities - by living and working alongside their counterparts over a period of time - enabled them to build the relationships and trust necessary to develop an equal relationship that encouraged local ownership.

When thinking about how VSO might embed participation within its programmes beyond the parameters of the Valuing Volunteering project, there are a number of factors related to the way in which VSO's programmes are structured which threaten to stand in the way. Valuing Volunteering found that volunteering is most effective at strengthening local agency and social capital when functioning as part of a multidisciplinary team where volunteer interventions are interconnected but also linked into other local networks and organisations. However, the evidence suggested that there were few examples of this interconnectedness and that more often than not volunteer interventions were still being designed as individual inputs, structured around separate time frames and working to a set of objectives that were not always linked into existing local activities and knowledge. By strengthening our understanding of the individual attributes of different volunteers, it ought to be possible to construct volunteer interventions as a series of interconnected efforts that complement each other, with some volunteers providing the more short-term technical inputs but supported by volunteers whose role is to work in a more relational way and ensure that these technical inputs are linked into the needs being articulated at a local level.

This links to the second challenge identified which is that if we become too focused on taking a programmatic approach and fail to factor in the flexibility to adapt our overarching objectives to the local context, then we will create a model that focuses on a very one-way delivery of top-down objectives. Findings from Valuing Volunteering suggested that rather than thinking in terms of projects and programmes, the way to ensure participation is embedded is to build long-term relationships with communities and local partners. Through long-term partnerships VSO and its local partners can learn, adapt and take risks together. It challenges the traditional perception of 'aid' or of VSO as the 'provider' and sets up the relationship as an equal partnership in which the risks of experimentation are being shared on both sides.

Making and acting on a genuine commitment to embed participation within our programmes is challenging, but the timing is right. The Millennium Development Goals (MDGs) taught us that in order to be sustainable, international development cooperation must look beyond technical and financial assistance to solutions that are devised from the ground up (Nath 2014: 3). We are seeing this reflected in the development of a set of new Sustainable Development Goals (SDGs, which will replace the MDGs) that promise to 'leave no-one behind' and for the first time talk not only about what needs to be implemented, but about how. As we have seen through Valuing Volunteering, volunteers are an essential and substantial component of the civil society workforce responsible for helping to implement these goals. Volunteers also help to create the spaces for open discussions and reflection, and support communities to have a strong voice in assessing what changes they want to see and how these should be implemented. This shift in the global development narrative presents a golden opportunity for organisations working with volunteers and for local volunteer groups to promote the role of volunteering in ensuring that the SDGs are implemented in a much more people-centred, community-driven and bottom-up way. 


\section{Notes}

1 For a copy of this case study, please contact Katie Turner at katie.turner@vsoint.org.

2 The Carood Watershed Model Forest Management Council (CWFMC) framework,

\section{References}

Aked, J. (2014) Viewes from the Watershed. How Citizens and Actors Describe Volunteering for Development. Reporting on the Impact of Volunteering for Natural Resource Management in Carood Watershed, Bohol, www.vsointernational.org/sites/vso_international/ files/valuing_volunteering_philipinnes_reportviews_from_the_watershed_0.pdf (accessed 21 July 2015)

Anderson, M.; Brown, D. and Jean, I. (2012) Time to Listen. Hearing People on the Receiving End of International Aid, Cambridge MA: CDA Collaborative Learning Projects

Burns, D. (2007) Systemic Action Research. A Strategy for Whole System Change, Bristol: Policy Press

Burns, D.; Picken, A.; Hacker, E.; Aked, J.; Turner, K.; Lewis, S. and Lopez Franco, E. (2015) The Role of Volunteering in Sustainable Development, Brighton and London: IDS and VSO

Chambers, R. (2014) 'Perverse Payment by Results: Frogs in the Pot and Straitjackets for Obstacle Courses', Participation, Power and Social Change, blog, https://participationpower.wordpress. com/2014/09/03/perverse-payment-by-resultsfrogs-in-a-pot-and-straitjackets-for-obstaclecourses/ (accessed 14 July 2015)

Coysh, J. (2015) 'People First Programme Architecture. An Overview and Suggestions for Moving Forward', unpublished report

Devereux, P. (2008) 'International Volunteering for Development and Sustainability: Outdated Paternalism or a Radical Response to Globalisation?', Development in Practice 18.3: 357-70

Hacker, E. (2014) Education and Volunteering in Nepal: A Case Study from the Hill and Terai Regions, www.vso.org.uk/about/what-we-do/ volunteering-for-development/valuingvolunteering (accessed 22 June 2015)

Howard, J.; Lewis, S. and Burns, D. (2015) 'VSO Participation and Governance Review', unpublished report

Ledwith, M. and Springett J. (2012) Participatory Practice. Community-based Action for Transformative Change, Bristol: Policy Press the overall objective of which is to ensure conservation and rehabilitation of the watershed.

Lewis (2015) Community Volunteering in Korogocho, www.vso.org.uk/about/what-we-do/ volunteering-for-development/valuingvolunteering (accessed 6 July 2015)

Lough, B. and Matthew, L. (2013) Measuring and Conveying the Added Value of International Volunteering, Forum Discussion Paper, www.france-volontaires. org/IMG/pdf/ivco2013_measuring_and_ conveying_the_added_value_of_international_ volunteering_lough.pdf (accessed 4 August 2015)

Nath, P. (2014) Volunteerism and the Post-2015 Agenda. VSO Report, www.vsointernational.org/sites/ vso_international/files/volunteerism-and-thepost-2015-agenda_tcm76-41498_0.pdf (accessed 21 July 2015)

Open Society Institute Network (2009) Mozambique: Democracy and Political Participation. A Review by AfriMAP and the Open Society Network for Southern Africa, www.afrimap.org/english/images/report/ AfriMAP-Moz-PolPart-EN.pdf (accessed 21 July 2015)

Picken, A. (2015) Spokes of a Wheel. A Participatory Community Led Volunteer Initiative, www.vsointernational.org/fighting-poverty/whatwe-do/volunteering-for-development/valuingvolunteering (accessed 21 July 2015)

Shahrokh, T. and Wheeler, J. (2014) Knowledge from the Margins. An Anthology from a Global Network on Participatory Practice and Policy Influence, IDS Report, Brighton: IDS

Van Eekelen, W. (2015) Second Independent Progress Review of VSO's Strategic Grant Agreement with DFID, VSO, www.vsointernational.org/sites/vso_ international/files/vsos_ipr2_final.pdf (accessed 14 July 2015)

VSO (2014) VSO's Global Theory of Change. Bringing People Together to Fight Poverty, www.vsointernational. org/sites/vso_international/files/vso-theory-ofchange-may2014.pdf (accessed 14 July 2015) VSO (2010) People First. VSO Strategy, www.vsointernational.org/sites/vso_ie/files/ documents/What $\% 20 \mathrm{we} \% 20 \mathrm{do} /$ people-firststrategy-2010.pdf (accessed 14 July 2015) 